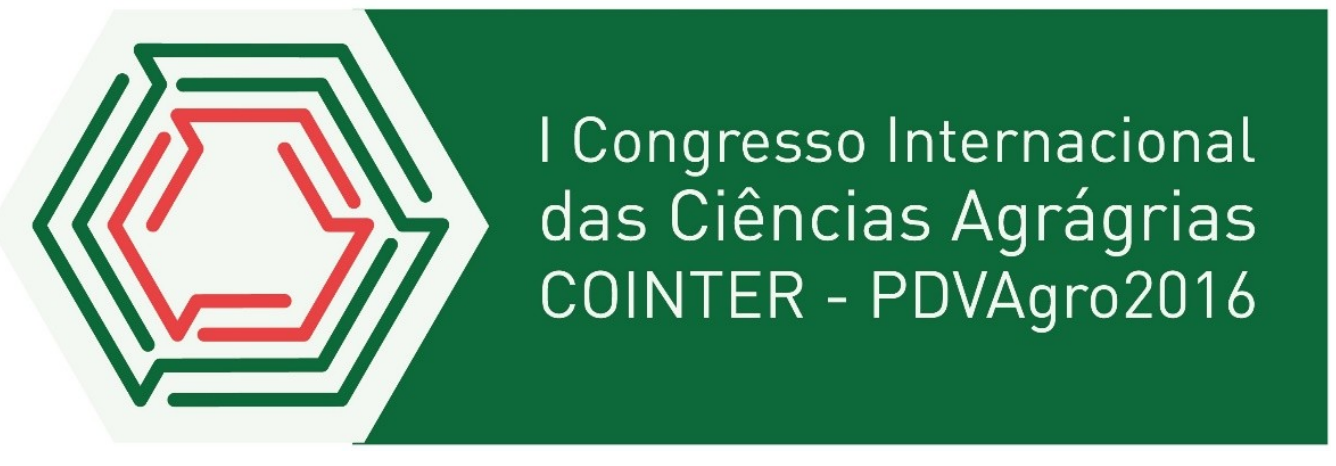

\title{
AVALIAÇÃO NUTRICIONAL DO QUIABEIRO SOB IRRIGAÇÃO E ADUBAÇÃO ORGÂNICA
}

\author{
Apresentação: Comunicação Oral \\ Daniel da Silva Ferreira'; Sebastião Mesquita de Oliveira Sobrinho²; Lucimara Ferreira de \\ Figueredo $^{3}$ Evandro Franklin de Mesquita $^{4}$
}

\section{Resumo}

A cultura do quiabo é uma das hortaliças mais cultivadas no estado da Paraíba, devido à baixa pluviosidade a constante irregularidades de chuvas, além do manejo nem sempre adequado em termos de adubação e irrigação tem comprometido a produção e o estado nutricional da cultura. Assim sendo, objetivou-se com esta pesquisa avaliar o estado nutricional das folhas de quiabeiro cultivar Santa Cruz, submetidos a adubação orgânica e lâminas de irrigaçã. O estudo foi desenvolvido em condições de campo, na Universidade Estadual da Paraíba, Campus IV. Utilizouse o delineamento em blocos casualizados distribuídos em esquema fatorial, 2 × 2 × 5 referente as lâminas de irrigação correspondentes a 50 e $100 \%$ da evapotranspiração da cultura (ETc), o solo sem e com cobertura morta com salsa brava (Ipomoeaasarifolia) triturada e desidratada e cinco doses de esterco bovino de relação $\mathrm{C} / \mathrm{N}=1: 18$, de modo a elevar o teor de matéria orgânica que o solo possui para 1,$8 ; 2,8 ; 3,8 ; 4,8$ e 5,8 . O método de irrigação adotado foi localizado com sistema por gotejamento. No início do florescimento avaliou-se os teores de macro e micronutrientes das folhas de quiabeiro. Diante do exposto, conclui-se que os teores foliares de macro e micronutrientes do quiabeiro foram maiores nas plantas irrigadas com lâminas de $100 \%$, em relação às cultivadas com $50 \%$ da ETc. A cobertura morta na superfície do solo proporcionou incremento nos teores foliares de macro e micronutrientes de folhas do quiabeiro. Por fim, o incremento da matéria orgânica no solo, influência de forma significativa a nutrição mineral da cultura do quiabo - Santa Cruz 47.

Palavras-Chave: Abelmoschus esculentus, adubação organomineral, manejo da irrigação.

\section{Introdução}

A cultura do quiabeiro (Abelmoschus esculentus(L.) Moench) é uma das hortaliças mais cultivadas no Estado da Paraíba, sendo a sétima hortaliça mais consumida depois do tomate (Lycopepersion esculentum L), batata doce (Ipomoea batatas L), cebola (Allium cepa), batata (Solanum tuberosum L), pimentão (Capsicum annuum L), coentro (Coriandrum sativum), alface

\footnotetext{
1 Graduando em Licenciatura em Ciências Agrárias, UEPB, Campus IV, Catolé do Rocha PB,danielzsilva3456@gmail.com

2 Graduando em Licenciatura em Ciências Agrárias, UEPB, Campus IV, Catolé do Rocha - PB, mesquita000@hotmail.com

${ }^{3}$ Doutoranda em Agronomia, UFPB, Campus II, Areia - PB, lucimara.ufpb@gmail.com

${ }^{4}$ Professor Doutor do Departamento de Agrárias e Exatas, UEPB, Campus IV, Catolé do Rocha, elmesquita4@uepb.edu.br
} 
(Lactuca sativa L.) e, no mesmo nível de consumo, da abobrinha (Cucurbita pelo L.), berinjela (Solanum melogena L.), pepino (Cucumis sativas L.) (SIC, 2013).

Pertence à família das Malváceas, produz em qualquer época do ano (OLIVEIRA et al., 2007), e constitui um alimento popular de alto valor nutricional, com aceitação crescente no mercado e está sendo produzido em maior escala pelos pequenos produtores em regime de agricultura familiar.

A capacidade produtiva das hortaliças, em geral, depende do regime pluviométrico e de umidade do solo. Nesse sentido, a baixa pluvisiodade inferior a $800 \mathrm{~mm}$ anuais, associada a constante irregularidade das chuvas são os fatores mais limitantes à obtenção de produtividades com viabilidade econômica das culturas em geral, inclusive do quiabeiro. Essa situação indica que o sistema produtivo das regiões semiáridas, como a do Alto Sertão Paraibano, é seguramente dependente da irrigação.

Outra séria inconveniência é a diminuição volumétrica dos mananciais de superfície e subterrâneos, em função dos insuficientes e mal distribuídos índices pluviométricos, elevadas temperatura do ar e do solo resultando com evaporação média de 9,41 $\mathrm{mm}$ dia no período da estiagem (SIC, 2013).

Uma das alternativas para a manutenção da pequena propriedade permanecer produzindo nas áreas semiáridas é irrigar com volume menor de água, em relação ao sistema de irrigação convencional, mas sem que haja perdas elevadas dos rendimentos e da qualidade da produção obtida. Dentre as práticas, para reduzir as perdas hídricas por evaporação, a cobertura morta da superfície do solo, com material vegetal ou plástico mantém o solo mais úmido, menos aquecido e reduz os efeitos das perdas hídricas por evaporação (TEÓFILO et al., 2012).

Conforme a literatura, a seleção de materiais para a cobertura vegetal do solo está associada à disponibilidade dos restos de cultura de cada região. Diversas espécies invasoras podem ser utilizadas como cobertura morta, dentre elas, a salsa, batata-salva e salsa brava (Ipomoea asarifolia). A cobertura morta exerce efeitos benéficos de natureza física na agregação e infiltração de água, química na melhoria da fertilidade e de natureza biológica no aumento da população e diversidade da biota edáfica.

Essas inconveniências climáticas, o baixo teor de matéria orgânica dos solos, exigem o suplemento anual de matéria orgânica, preferencialmente de origem animal pela disponibilidade e de fácil aquisição. Esse insumo apesar do seu baixo conteúdo dos macronutrientes (CAVALCANTE et al., 2010) exerce ação benéfica na melhoria física e biológica com reflexo positivo na fertilidade do solo e na produção das culturas. 
Diante do exposto, objetivou-se com esta pesquisa avaliar a influência da adubação orgânica e o manejo de irrigação sobre os teores de macro e micronutrientes no alto sertão paraibano.

\section{Fundamentação Teórica}

A microrregião de Catolé do Rocha, pertencente à mesorregião do Alto Sertão paraibano, formada pelos municípios de Belém do Brejo do Cruz, Bom Sucesso, Brejo do Cruz, Brejo dos Santos, Catolé do Rocha, Jericó, Lagoa, Mato Grosso, Riacho dos Cavalos, São Bento e São José do Brejo do Cruz, apresenta uma grande diversidade dos seus sistemas produtivos com boa possibilidade ambiental para o desenvolvimento de novas atividades agropecuárias, destacando-se a produção de plantas hortícolas. Nesse contexto, a cultura do quiabo pode ser inserida devido sua adequada adaptação às condições do clima semiárido, associado à sua expressiva importância na produção hortícola.

A região possui também amplas áreas agrícolas disponíveis à expansão da agricultura familiar com viabilidade econômica caso haja a adoção de inovações tecnológicas como técnicas para reduzir as perdas hídricas por evaporação resultando em irrigação das plantas com menor reposição de água, em relação ao cultivo convencional, sem perdas comprometedoras da produção. Para isso, é necessário também um rígido cronograma de adubação organomineral à cultura, de modo obterem-se índices de rendimentos economicamente viáveis.

\section{Metodologia}

O estudo foi realizado no campo durante o período de setembro de 2015 a março de 2016 na Universidade Estadual da Paraíba, Campus IV, Setor de Agroecologia, situado no município de Catolé do Rocha, PB (6 $20^{\prime} 38^{\prime}$ 'S, 37 44'48'’W e altitude de $270 \mathrm{~m}$ ). Segundo classificação de Koppen o clima da região é do tipo BSw'h', caracterizado por um semiárido quente, com duas estações distintas, uma chuvosa com precipitação irregular e outra sem precipitação. O solo foi classificado como Neossolo Flúvico Eutrófico (EMBRAPA, 2013).

Os tratamentos foram distribuídos em blocos casualizados em esquema fatorial 2 × 5 × 2 , referentes a duas lâminas de irrigação de 100 e 50\% baseado na evapotranspiração da cultura (ETc), cinco doses de esterco de bovino de relação $\mathrm{C} / \mathrm{N}$ de 18:1, no solo sem e com cobertura morta, com quatro repetições, cada parcela continha três linhas de 3,2 $\mathrm{m}$ de comprimento e $2 \mathrm{~m}$ de largura, com área de $6,4 \mathrm{~m}^{2}$ sendo que cada linha tinha nove plantas, e a parcela foi composta por 15 plantas, totalizando 80 parcelas experimentais. 
Utilizou-se como cobertura morta restos de vegetais de salsa desidratada triturada (Ipomoea asarifolia), em camada de $5 \mathrm{~cm}$ de espessura.

As covas foram abertas nas dimensões de $30 \mathrm{~cm}$ x $30 \mathrm{~cm}$ x $30 \mathrm{~cm}$, no espaçamento de $0,8 \mathrm{~m}$ entre plantas e $1 \mathrm{~m}$ entre linhas, e preparadas com material de solo dos primeiros $30 \mathrm{~cm}$, adicionouse 16 g cova $^{-1}$ de superfosfato simples $\left(20 \%\right.$ de $\left.\mathrm{P}_{2} \mathrm{O}_{5}\right)$ (RIBEIRO et al., 1999) e esterco bovino de relação $\mathrm{C} / \mathrm{N}$ de 18:1 para elevar o teor de matéria orgânica que o do solo possuía de 1,8\% para 2,8; $3,8 ; 4,8$ e $5,8 \%$ (Tabela 1$)$.

Tabela 1: Caracterização química do esterco bovino utilizado como fonte de matéria orgânica. Fonte: Laboratório de

\begin{tabular}{|c|c|c|c|c|c|c|c|c|c|c|c|c|}
\hline 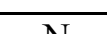 & 2 & $\bar{T}$ & $\sigma_{0}$ & & & & & & & & 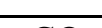 & 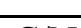 \\
\hline $1 \mathrm{~s}$ & $\mathrm{~g} \mathrm{~kg}$ & 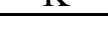 & & & & \multicolumn{4}{|c|}{$\mathrm{mg} \mathrm{kg}^{-1}$} & \multicolumn{3}{|c|}{$\mathrm{g} \mathrm{kg}^{-1} \ldots \ldots$} \\
\hline 12.76 & 257 & 1679 & 1555 & 402 & 559 & 60 & 22 & 8550 & 325 & $\begin{array}{l}\cdots 50 \\
3960\end{array}$ & 2297 & $18: 1$ \\
\hline
\end{tabular}

A semeadura do quiabeiro (Abelmoschus esculentus(L.) Moench) cultivar Santa Cruz 47, foi realizada através de plantio direto, sendo semeadas cinco sementes por cova. Quando as plantas estavam com três folhas definitivas foi realizado o desbaste, mantendo-se apenas a planta mais vigorosa por cova (Tabela 2).

Tabela 2: Valores de cada dose de matéria orgânica aplicada e suas respectivas equivalência nas covas. Fonte Própria

\begin{tabular}{cc}
\hline $\begin{array}{c}\text { Doses de matéria } \\
\text { orgânica aplicada }\end{array}$ & $\begin{array}{c}\text { Valores de } \\
\text { esterco bovino }\end{array}$ \\
\hline$(\%)$ & g cova $^{-1}$ \\
$1,8 *$ & 0,00 \\
2,8 & 1081,00 \\
3,8 & 2162,00 \\
4,8 & 3243,00 \\
5,8 & 4324,00 \\
\hline
\end{tabular}

Aos 20, 40 e 60 dias após a semeadura foram realizados a adubação de cobertura com base na análise de solo (RIBEIRO et al., 1999), aplicando-se $4 \mathrm{~g}$ cova $^{-1}$ de sulfato de amônio e $3 \mathrm{~g} \mathrm{cova}^{-1}$ de cloreto de potássio

A irrigação das plantas foi realizada diariamente pelo método de irrigação localizada, por gotejamento, de acordo com a evapotranspiração da cultura-ETc $\left(\mathrm{mm} \mathrm{d}^{-1}\right)$. O cálculo foi feito com base na evapotranspiração de referência (Eto, $\mathrm{mm} \mathrm{d}^{-1}$ ), estimada pelo tanque Classe A e corrigida pelo Kc da cultura de acordo com o estágio de desenvolvimento da planta.

A diferenciação das lâminas foi feita aos 15 dias após a semeadura (DAS) tal como a aplicação da cobertura morta. 
No início da floração (45 DAS), foi colhida a folha D de quatro plantas de cada tratamento para determinação dos teores de N, P, K, B, Cu e Zn para avaliação do estado nutricional da cultura (FILGUEIRA, 2013), adotando as metodologias contidas em Malavolta, Vitti e Oliveira (1997).

Os resultados foram submetidos à análise de variância para diagnóstico de efeitos significativos pelo teste $\mathrm{F}$, comparação de médias para os fatores qualitativos e regressão polinomial para os fatores quantitativos, empregando o AgroEstat Sistema para Análises Estatísticas (BARBOSA; MALDONATO JÚNIOR, 2015).

\section{Resultados e Discussão}

A composição mineral de folhas de quiabeiro respondeu significativamente aos tratamentos referentes aos níveis de matéria orgânica e lâminas de irrigação a 1 e a 5\% de significância. A interação entre lâminas de irrigação e níveis de matéria orgânica foi significativa, exceto para os teores foliares de $\mathrm{B}$ e $\mathrm{Zn}$ nos teores foliares. A interação entre lâminas de irrigação, níveis de matéria orgânica e cobertura morta foi significativa para os teores foliares de $\mathrm{K}$ e $\mathrm{B}$, indicando dependências dos fatores.

O aumento dos níveis de matéria orgânica do solo (MOS) estimulou a acumulação de nitrogênio de folhas do quiabeiro com valores máximos de $\left(37,85\right.$ e $\left.35,99 \mathrm{~g} \mathrm{~kg}^{-1}\right)$ referentes as doses estimadas de 4,32 e 4,98\% do insumo para as plantas irrigadas com $100 \%$ e 50\% ETc, respectivamente (Figura 1A), fato confirmado por Cavalcante et al. (2010) que observaram incremento no teor de nitrogênio nas folhas de quiabeiro com aumento de percentual de matéria orgânica no solo. O nitrogênio $(\mathrm{N})$ foi o elemento mais acumulado nas folhas de quiabo e isto pode estar relacionado a constituição do elemento que é constituinte de ácidos nucléicos e da clorofila (MALAVOLTA, 2008), fato também confirmado por Galati et al. (2013).

A redução da lâmina de irrigação de 100 para 50\% ETc resultou na perda de acumulação foliar de nitrogênio de 37,8 para 35,99 $\mathrm{g} \mathrm{kg}^{-1}$, resultando numa perda de 5,17\%. A superioridade é resposta do solo mais úmido, quando irrigado com a maior lâmina de água resultando em maior área de contato do íon $\mathrm{N}$ com a superfície das raízes.

Os teores de fósforo apresentaram comportamentos semelhantes ao de nitrogênio para o desdobramento dos níveis de matéria orgânica dentro das lâminas de irrigação ajustando-se ao modelo quadrático, com valores máximos de 4,58 e $4,11 \mathrm{~g} \mathrm{~kg}^{-1}$ para os tratamentos $100 \%$ ETc e $50 \%$ da ETc referentes às doses máximas estimadas de 4,36 e 4,45\% nas plantas com lâminas de irrigação de 10 e 50\% da evapotranspiração da cultura (ETc), respectivamente (Figura 1B). Com a redução do fornecimento de água de 100 para 50\% ETc resultou numa perda da acumulação foliar 
de $\mathrm{P}$ de 11,43\%. As plantas mantidas em condições adequados de umidade do solo proporcionam maior eficiência fotossintética com maiores taxas de respiração e transpiração, e maior energia para vencer a resistência à penetração das raízes no solo (HOFFMANN; JUNGK, 1995). Este resultado foi semelhante ao obtido por Adewole e Ilesanmi (2011) que obtiveram plantas nutricionalmente equilibradas, adubando as plantas de quiabo com adubo orgânico, obtiveram rendimentos compatíveis ao cultivo convencional.

Figura 1: Teor de nitrogênio (A) e fósforo (B) das folhas do quiabeiro cultivada sob níveis de matéria orgânica do solo e lâminas de irrigação. Catolé do Rocha - PB, 2016. Fonte Própria

A

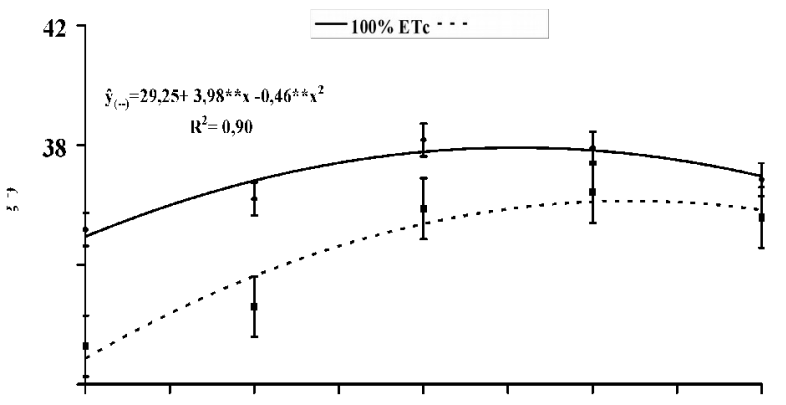

$\mathrm{B}$

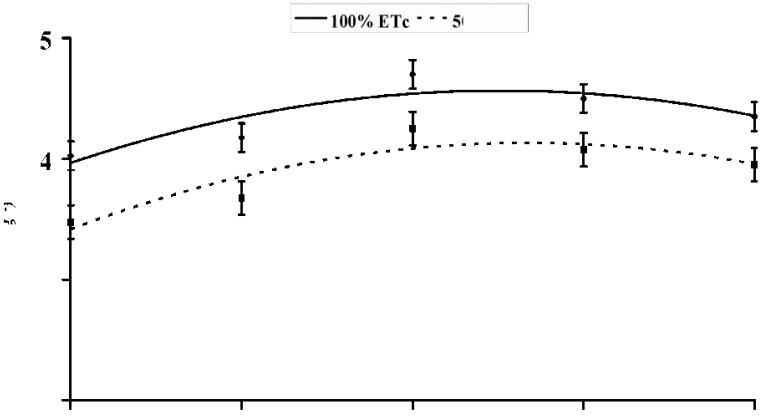

Nas plantas do solo com cobertura morta, irrigadas com lâmina de água correspondente a $100 \%$ da ETc, os teores de potássio aumentaram linearmente em $0,51 \mathrm{~g} \mathrm{~kg}^{-1}$ de $\mathrm{K}^{+}$por aumento unitário do insumo orgânico aplicado, com o maior valor de $21,66 \mathrm{~g} \mathrm{~kg}^{-1}$ na maior nível de MOS. Nas mesmas condições de cobertura, as plantas tratadas com lâminas de irrigação de $50 \%$ da ETc tiveram os teores de potássio foliares elevados até o valor máximo $21,05 \mathrm{~g} \mathrm{~kg}^{-1}$ na dose máxima estimada de 5,6\% de matéria orgânica aplicada ao solo (Figura 2A). Esses resultados foram superiores aos 5,46 $\mathrm{g} \mathrm{kg}^{-1}$ de $\mathrm{K}$ na matéria seca do limbo de folhas e de quiabo, observado por Galati et al. (2013), no estado de São Paulo, fertilizando as plantas com N-P $\mathrm{P}_{2} 0-\mathrm{K}_{2}-0$. Nas plantas dos tratamentos sem cobertura morta, os dados se ajusturam ao modelo polinomial quadrático (Figura 2B). Independentemente da cobertura morta, os maiores teores de potássio nas folhas de quiabeiro foram maiores nas plantas irrigadas com 100\% ETc em comparação as plantas irrigadas com 50\% ETc.

Esse é o segundo nutriente mais requerido pela planta, além de atuar como ativador enzimático em mecanismos de síntese e degradação de compostos orgânicos e também participa no mecanismo de abertura e fechamento dos estômatos e osmorregulação, dentre outras funções (MALAVOLTA, 2008). 
Figura 2: Teor de potássio nas folhas do quiabeiro cultivado sob níveis de matéria orgânica no solo, lâminas de irrigação com (A) e sem (B) cobertura morta. Catolé do Rocha - PB, 2016. Fonte Própria

A

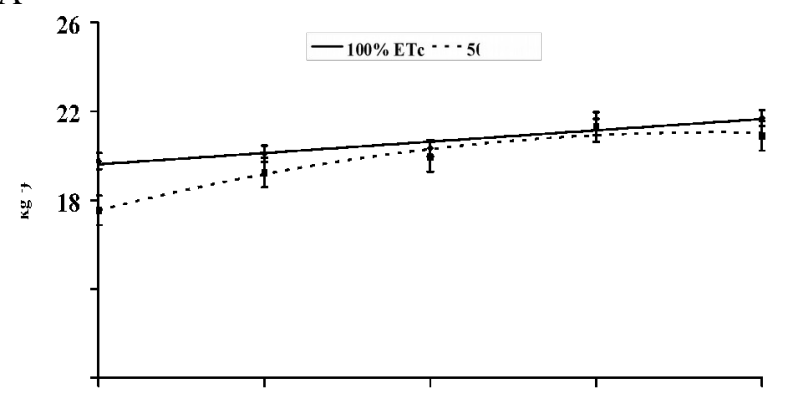

B

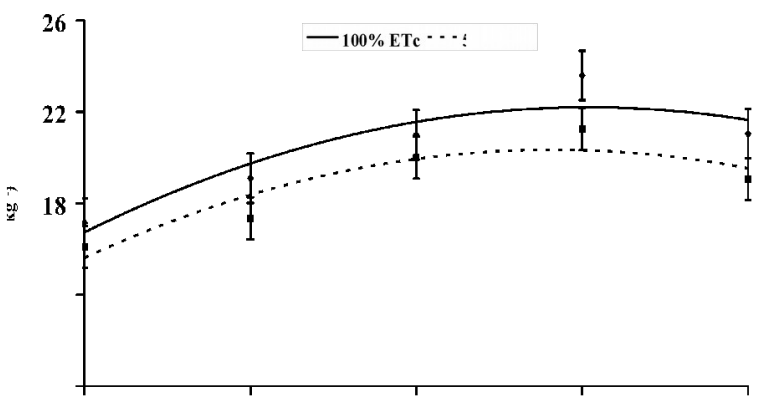

A acumulação de boro nas folhas de quiabeiro (Figura 3) ajustou-se ao modelo linear crescente com incrementos de $\left(0,93\right.$ e $\left.0,73 \mathrm{mg} \mathrm{kg}^{-1}\right)$ e $\left(1,92\right.$ e $\left.141 \mathrm{mg} \mathrm{kg}^{-1}\right)$ para aumento unitário do insumo orgânico com valores máximos estimados de $\left(56,08\right.$ e 49,88 $\left.\mathrm{mg} \mathrm{kg}^{-1}\right)$ e $(56,51$ e $50,10 \mathrm{mg}$ $\mathrm{kg}^{-1}$ ) para as plantas irrigadas com $100 \%$ e $50 \%$ ETc com e sem cobertura morta na superfície do solo (Figura 3A e B). O aumento nível de matéria orgânica do solo proporcionou incremento no teor de B na matéria seca de folhas de quiabo, conforme Raij (2011).

Figura 3: Teor de boro nas folhas do quiabeiro cultivado sob níveis de matéria orgânica no solo, lâminas de irrigação

A com (A) e sem (B) cobertura morta. Catolé do Rocha - PB, 2016. Fonte Própria

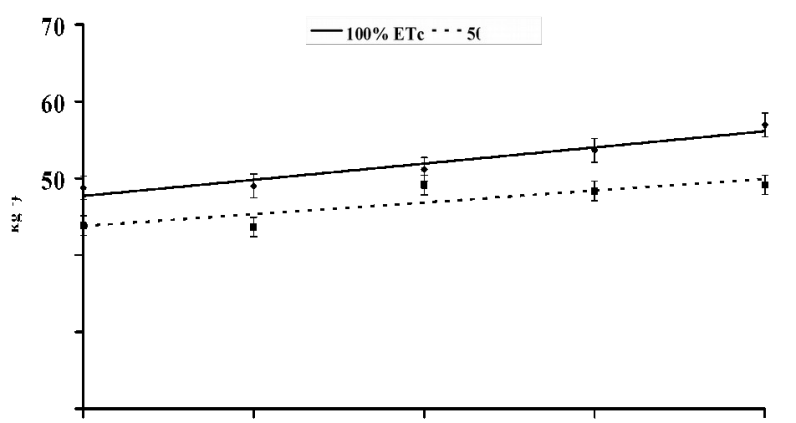

$\mathrm{B}$

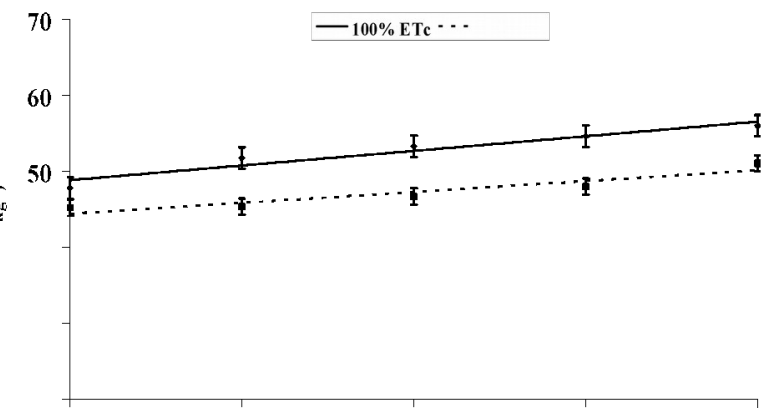

$\mathrm{O}$ teor de $\mathrm{Cu}$ nas folhas de quiabeiro ajustaram ao modelo polinomial quadrático com valores máximos de 11,26 e 10,19 $\mathrm{mg} \mathrm{kg}^{-1}$ referentes os níveis estimados de 3,64 e 4,08\% de matéria orgânica nas plantas irrigadas com $100 \%$ e $50 \%$ ETc, respectivamente (Figura 4A). Nas plantas irrigadas com $100 \%$ ETc sobressaíram àquelas irrigadas com $50 \%$ ETc com uma superioridade de 10,5\%. Essa situação, evidencia que a cultura sob deficiência de água no solo, 
principalmente, no período de maior temperatura do ambiente, sofre perca de turgor celular, que ocasiona em menor área foliar exposta a radiação solar, resultando na diminuição da taxa de transpiração, com efeito, em menor absorção de água e nutrientes essenciais contidos na solução do solo.

A adição de matéria orgânica promoveu aumento no teor foliar de $\mathrm{Zn}$ nas plantas até o nível máxima estimada de 4,00\% de MOS, correspondente ao maior teor de 46,69 $\mathrm{mg} \mathrm{kg}^{-1}$ (Figura 4B).

$\mathrm{O}$ teor de $\mathrm{Zn}$ nas folhas de quiabo foram maiores nas plantas formadas sem stress hídrico em comparação àquelas formadas sob déficit hídrico, cujos valores foram de 44,46 e 40,76 $\mathrm{mg} \mathrm{kg}^{-1}$. Esses resultados indicam que, ao reduzir a lâmina de irrigação de 100 para 50\% da ETc, as plantas sofrem um declínio na acumulação foliar de zinco de 9,07\% (Figura 4C).

Figura 4: Teores de $\mathrm{Cu}(\mathrm{A})$ e $\mathrm{Zn}$ nas folhas do quiabeiro cultivada sob níveis de matéria orgânica do solo, lâminas de irrigação, com (B) e sem (C) cobertura morta. UEPB, Catolé do Rocha - PB, 2016. Fonte Própria

A

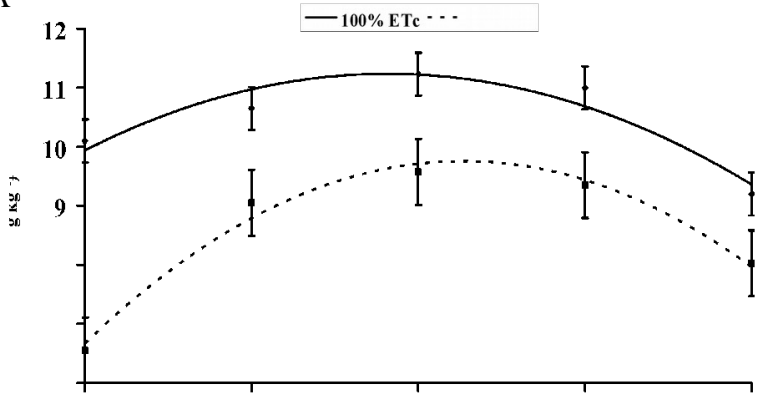

B

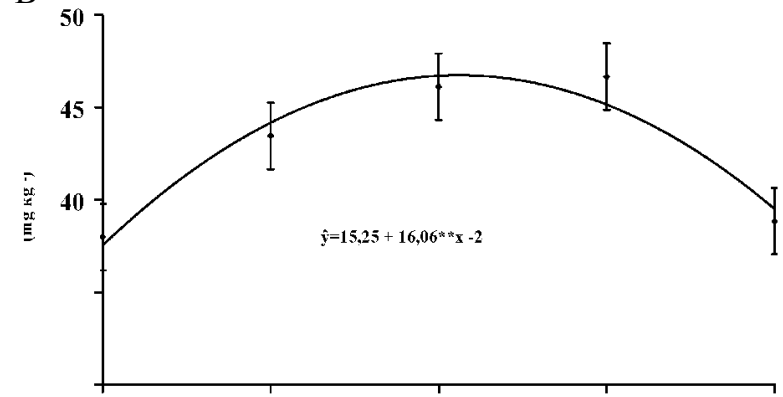

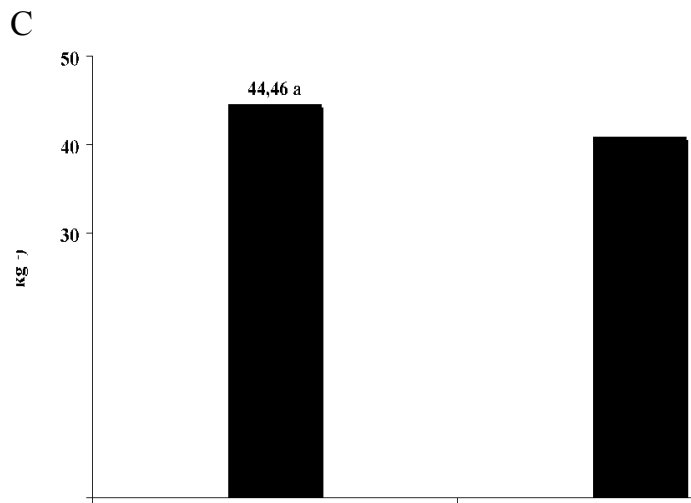




\section{Conclusões}

Os teores foliares de macro e micronutrientes das folhas do quiabeiro foram maiores nas plantas irrigadas com lâminas de 100\% em relação às cultivadas com 50\% da ETc;

O incremento da matéria orgânica no solo influência de forma significativa o desenvolvimento a nutrição mineral da cultura do quiabo - Santa Cruz 47;

A cobertura morta na superfície do solo proporcionou incremento nos teores foliares de macro e micronutrientes do quiabeiro.

\section{Referências}

ADEWOLE, M. B.; ILESANMI, A. O. Effects of soil amendments on the nutritional quality of okra (Abelmoschus esculentus [L.] Moench). Journal of Soil Science and Plant Nutrition., v. 11, n. 3, p. 45-55, 2011.

BARBOSA, J.C.; MALDONADO JÚNIOR, W. Experimentação agronômica \& AgroEstat: Sistema para análises estatísticas de ensaios agronômicos. Jaboticabal: gráfica Multipress Ltda,2015, 396 p.

CAVALCANTE, L.F.; DINIZ, A.A.; SANTOS, L.C.F.; REBEQUI, A.M.; NUNES, J.C.; BREHM, M.A.S. Teores foliares de macronutrientes em quiabeiro cultivado sob diferentes fontes e níveis de matéria orgânica. Semina: Ciências Agrárias, Londrina, v. 31, n. 1, p. 19-28, 2010.

EMBRAPA. Centro Nacional de Pesquisa de Solos. Sistema Brasileiro de Classificação de Solos. 3. ed. Brasília, DF: Embrapa Solos 2013. 353p.

FILGUEIRA. F. A. R. Novo manual de olericultura- agrotecnologia moderna na produção e comercialização de hortaliças. $3^{a}$ edição. Viçosa: Editora UFV, 421p, 2013.

GALATI, V.C.; CECILIO FILHO, A.B.; GALATI, V.C.; AILVES, A.U. Crescimento e acúmulo de nutrientes da cultura do quiabeiro. Semina: Ciências Agrárias, Londrina, v. 34, n. 1, p. 191$200, .2013$.

HOFFMANN, C.; JUNGK, A. Growth and phosphorus supply of sugar beet as affected by soil compaction and water tension. Plant and Soil, Dodrecht, v. 176, n. 1, p. 15-25, 1995.

MALAVOLTA, E. O futuro da nutrição de plantas, tendo em vista aspectos agronômicos, econômicos e ambientais. Informações Agronômicas, n.121, p.1-10, 2008.

MAlAVOlTA, E.; VITTI, G. C.; OLIVEIRA, S. A. Avaliação do estado nutricional das plantas:

princípios e aplicações. Piracicaba: POTAFOS, 1997. 201 p.

OLIVEIRA R. D. L; SILVA M. B.; AGUIAR N. D. C; BÉRGAMO F. L. K; COSTA A. S. V.; PREZOTTI L. Nematofauna associada à cultura do quiabo na região leste de Minas Gerais. Horticultura Brasileira, v. 25, p.88-93, 2007. 
RAIJ, B. V. Fertilidade do solo e manejo de nutrientes. Piracicaba: International Plant Nutrition Institute, $2011.420 \mathrm{p}$.

RIBEIRO, A. C.; GUIMARÃES, P. T. G.; ALVAREZ, V. H. (Eds). Comissão de Fertilidade do solo do Estado de Minas Gerais. Viçosa, 359 p. 1999.

SIC: Sistema de informação ao consumidor. Catolé do Rocha: Prefeitura municipal. 2013.

TEÓFILO, T.M.S.; FREITAS, F.C.L.; MEDEIROS, J.F.; FERNANDES, D.; GRANGEIRO, L.C; TOMAZ, H.V.Q.; RODRIGUES, A.P.M.S. Eficiência no uso da água e interferência de plantas daninhas no meloeiro cultivado nos sistemas de plantio direto e convencional. Planta Daninha, v.30, n.3, p.547-556, 2012. 